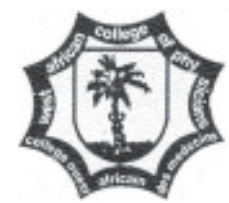

WEST AFRICAN JOURNAL OF MEDICINE

ORIGINAL ARTICLE

\title{
Underutilization of Vaginal Hysterectomy and its Impact on Residency Training
}

\author{
La Sous-utilisation de l'hystérectomie vaginale et l'impact de fils sur \\ Entraînement de Résidence
}

A. N. Ocheke*, C. C. Ekwempu, J. Musa

\begin{abstract}
BACKGROUND: The advantages of vaginal hysterectomy over abdominal hysterectomy include lower morbidity, shorter hospital stay, and reduced cost to the patient. It is, therefore, important to pass the required skill for vaginal hysterectomy unto trainees.

OBJECTIVE: To determine the proportion of vaginal hysterectomies done in a residency training institution in Nigeria and its possible impact on the proficiency of future gynaecologists in performing the procedure.

METHODS: A chart review was done on all documented cases of hysterectomies for benign gynaecological conditions done in Jos University Teaching Hospital, over a four-year period (January 2002 to December 2005). Case files of patients who had hysterectomy during the study period were retrieved and the relevant information obtained for analysis of frequencies and percentages.

RESULTS: A total of 94 hysterectomies for benign gynaecological conditions were done during the study period. Nine $(\sim \mathbf{1 0 \%})$ vaginal hysterectomies were done. All the vaginal hysterectomies performed were for uterovaginal prolapse by consultants. However, $45(53 \%)$ of the abdominal hysterectomies were performed by consultants and $40(47 \%)$ by residents.

CONCLUSION: This study suggests that residents' exposure and training on the act of vaginal hysterectomy is inadequate. This has potential implications on future gynaecologist proficiency to perform this method of surgery that has documented advantages and better outcome for patients. WAJM 2009; 28(5): 323-326.
\end{abstract}

Keywords: Hysterectomy, vaginal hysterectomy, abdominal hysterectomy, residency training, Nigeria.

\section{RÉSUMÉ}

CONTEXTE: Les avantages de l'hystérectomie vaginale plus de l'hystérectomie abdominale comprenant une baisse de la morbidité, la durée d'hospitalisation et un coût réduit pour le patient. Il est donc important de passer de la compétence requise pour l'hystérectomie vaginale vers les stagiaires.

OBJECTIF : Déterminer la proportion d'hystérectomies par voie vaginale exécutée dans un établissement de formation en résidence au Nigeria et son impact possible sur les compétences des gynécologues avenir dans l'accomplissement de la procédure.

MÉTHODES: Un examen des dossiers a été effectué sur tous les cas documentés d'hystérectomies pour les affections gynécologiques bénignes fait dans Jos University Teaching Hospital, sur une période de quatre ans (Janvier 2002 à Décembre 2005). Des dossiers de patients ayant subi une hystérectomie au cours de la période d'étude ont été récupérés et des renseignements pertinents obtenus pour l'analyse des fréquences et des pourcentages.

RÉSULTATS: Un total de 94 hystérectomies pour les affections gynécologiques bénignes ont été réalisées au cours de la période d'étude. Neuf ( 10\%) une hystérectomie vaginale ont été accomplis. Tous les hystérectomies vaginales ont été effectuées pour prolapsus utéro-vaginal par des consultants. Toutefois, 45 (53\%) de l'hystérectomie abdominale ont été réalisées par des consultants et 40 (47\%) par les résidents.

CONCLUSION: Cette étude suggère que l'exposition des résidants et de formation sur la Loi de l'hystérectomie vaginale est insuffisante. Ceci a des implications potentielles sur la maîtrise gynécologue l'avenir pour réaliser cette méthode de chirurgie qui a consigné les avantages et un meilleur pronostic pour les patients. WAJM 2009; 28 (5): 323-326.

Mots-clés: hystérectomie, l'hystérectomie par voie vaginale, une hystérectomie abdominale, formation en résidence, au Nigeria.

Department of Obstetrics and Gynaecology, Jos University Teaching Hospital.

Correspondence: Dr Ocheke Amaka N. Department of Obstetrics and Gynaecology, Jos University Teaching Hospital, P MB 2076, Jos, Plateau State. Tel: 234-8036135114. Email: amakaocheke@yahoo.com

Abbreviations: JUTH, Jos University Teaching Hospital. 


\section{INTRODUCTION}

The vaginal route has been said to be the gynaecologist's route of surgery. ${ }^{1}$ However, abdominal hysterectomy remains the predominant method of uterine removal in most parts of the world, in spite of the evidence that vaginal hysterectomy offers advantages in regard to operative time, complication rates, return to normal activities and overall cost of treatment in benign conditions. ${ }^{2-5}$

Vaginal hysterectomy accounts for approximately $25 \%$ of hysterectomies in the United States of America, ${ }^{6} 40-50 \%$ in France and Australia, ${ }^{4,7}$ 28\% in Saudi Arabia ${ }^{9}$ and $10-23 \%$ from various reports from Nigeria. ${ }^{10-13}$ Uterine fibroid has been reported as the most common indication for abdominal hysterectomy and uterovaginal prolapse for vaginal hysterectomy. ${ }^{4,69-14}$ Limited or obsolete practice guidelines, safety concerns for undertaking a vaginal procedure with probable co-existing abdominal pathology, cost of vaginal hysterectomy and operator preferences for abdominal over vaginal procedures are among the documented factors for the underutilization of vaginal hysterectomy. ${ }^{5,14}$ It has also been argued that vaginal hysterectomy may not be as technically easy among Nigerians as compared to those in developed countries because of severe pelvic adhesions frequently encountered in Nigerian women requiring hysterectomy. ${ }^{10,12}$

Efforts have been made in recent years to promote vaginal hysterectomy in western countries. ${ }^{2,14}$ It has been advocated that the vaginal route should be the route of choice for hysterectomies for benign gynaecological conditions except there are contraindications. ${ }^{1-3}$ The contraindications to vaginal hysterectomy include a uterus more than 12 weeks' gestation size, restricted uterine mobility, limited vaginal space, adnexal pathology, vesicovaginal fistula repair, cervix flushed with vagina, and invasive cancer of the cervix. ${ }^{1,14,15}$ Application of practice guidelines for the selection of the route of hysterectomy has been found to increase the number of vaginal hysterectomies performed. ${ }^{3,14,15}$ Evidence also has shown that transvaginal hysterectomy is both feasible and optimum for types of patients who have long been considered inappropriate candidates for the vaginal route. ${ }^{2,14}$ This practice in a study in the United States of America reduced the ratio of abdominal to vaginal hysterectomy from 3:1 to $1: 11 .{ }^{15}$ Application of these guidelines has also been found to increase the indications for vaginal hysterectomy which in many reports has been done primarily for uterovaginal prolapse. ${ }^{6,10,17}$

Given the emerging evidence of the advantages of vaginal approach over abdominal for hysterectomy procedures, it is regrettable that the state of education in many residency programmes is not providing a level of surgical competency to meet this charge. ${ }^{3}$ The increased use of vaginal hysterectomy would provide more opportunities for residents to be better trained in this procedure. ${ }^{5,15} \mathrm{~A}$ study in Japan showed that performing 25 vaginal hysterectomies or less during a three-year residency training programme was insufficient to for residents to gain proficiency in the procedure. ${ }^{18}$ Another problem with lack of proficiency in performing vaginal hysterectomy is that such gynaecologists are not always in a position to offer their patients a genuine choice of treatment options hence efforts need to be made to improve training in gynaecological surgery for the younger generation of gynaecologists. ${ }^{5}$

This study was carried out, therefore, to determine the frequency of vaginal hysterectomy especially as it relates to the abdominal route and its impact on residency training.

\section{SUBJECTS, MATERIALS, AND METHODS}

The study was retrospective and carried out in the Jos University Teaching Hospital, Jos which is located in Northcentral Nigeria, West Africa.

All hysterectomies recorded in the operation register of the department of Obstetrics and Gynaecology theatre between January 2002 and December 2005 were reviewed. The case notes of patients who had hysterectomy for benign gynaecological conditions were retrieved and analyzed with regard to socio-demographic characteristics, diagnosis, type and route of surgery, operative findings, cadre of surgeon, and post-operative complications. Patients whose folders had insufficient information were excluded from the study.

There were 124 hysterectomies done for benign gynaecological conditions during the study period and of these only 94 folders with the required information could be retrieved. The information from the case records was transcribed unto a proforma already designed for the purpose. These forms were then utilized in the final analysis using Epi-info 2003 statistical software for percentages.

\section{RESULTS}

There were a total of 94 folders with complete information out of 124 hysterectomies done for benign gynaecological conditions, giving a retrieval rate of $76 \%$. The ages of the patients ranged from 30-64 years with a mean of $45.5 \pm 7.6$ years. The majority of the patients were aged 40 years and above. The parities of the patients ranged from 0 to 19 with a mean of $4.7 \pm 3.2$. Nullipara accounted for $11 \%$, parity of one-four accounted for $41 \%$ while parity of five and more accounted for $48 \%$.

Nine vaginal hysterectomies and 85 abdominal hysterectomies were performed, giving a ratio of 1:9.4. All of the vaginal hysterectomies were done for uterovaginal prolapse while the most common indications for abdominal hysterectomy were uterine fibroids and cervical intraepithelial neoplasia (Table 1). A uterine size consistent with or less

Table 1: Distribution of types of Surgery by Indications

\begin{tabular}{lll}
\hline Indication & \multicolumn{2}{c}{$\begin{array}{c}\text { Type of Surgery } \\
\text { (Number(\%)) }\end{array}$} \\
\cline { 2 - 3 } & AH & VH \\
\hline Fibroid & $59(62.8)$ & 0 \\
CIN & $21(22.3)$ & 0 \\
UV prolapse & 0 & $9(9.6)$ \\
Polyp & $1(1.1)$ & 0 \\
Endometrial & $1(1.1)$ & 0 \\
hyperplasia & & \\
Adenomyosis & $1(1.1)$ & 0 \\
DUB & $2(2.1)$ & 0 \\
\hline Total & $\mathbf{8 5}(90.4)$ & $9(9.6)$ \\
\hline
\end{tabular}

*AH, Abdominal hysterectomy; VH, Vaginal hysterectomy; CIN, Cervical Intraepithelial Neoplasia; UV, Uterovaginal; DUB, Dysfunctional Uterine Bleeding. 
than 12 weeks' gestation size was found in 46 patients (49\%) and 48 patients $(51 \%)$ had uterine sizes greater than 12 weeks' gestation size. Of those who had a uterine size consistent with or less than 12 weeks' gestation, nine (10\%) of them had a vaginal hysterectomy carried out on them while the remainder had abdominal hysterectomy. All those with uterine size greater than 12 weeks' gestation size had abdominal hysterectomy.

Pelvic adhesions were present in 35 patients $(37 \%)$ and absent in 59 patients (63\%). The presence of pelvic adhesions with a uterine size consistent with or less than 12 weeks' gestation occurred in 12 (13\%) patients while 34 patients $(37 \%)$ had a uterine size consistent with or less than 12 weeks' gestation size with no pelvic adhesions.

Consultants performed $45(53 \%)$ of the abdominal hysterectomies and all the vaginal hysterectomies while Senior Registrars performed 40 (47\%) of the abdominal hysterectomies. Postoperative complications occurred in 23 patients $(27 \%)$ who had abdominal hysterectomies but there were no complications in those who had vaginal hysterectomy. The complications following abdominal hysterectomy included bladder injury, fistulae, ureteric injuries, urinary tract infection wound infection and thrombophlebitis.

\section{DISCUSSION}

The frequency of vaginal hysterectomy accounting for $10 \%$ of hysterectomies in our hospital is lower than findings from other centres in Nigeria where figures between $12 \%-23 \%$ have been quoted. ${ }^{10-12}$ These rates are even lower than what has been reported from the United States (25\%) and France $(50 \%) .^{4,6,7}$ This result is indicative of the fact that vaginal hysterectomy is underutilized in our centre as compared with abdominal hysterectomy for benign gynaecological conditions. Despite the higher use of vaginal hysterectomy in the United States and Europe, efforts are still being made to further increase the utilization of the vaginal route for hysterectomies because of the obvious advantages of the use of this route..$^{3-7,14}$

It has been advocated that the vaginal route should be the route of choice for hysterectomies for benign gynaecological conditions except where there are contraindications. ${ }^{1-3}$ These contraindications to vaginal hysterectomy include a uterus more than 12 weeks' gestation size, restricted uterine mobility, limited vaginal space, adnexal pathology, vesicovaginal fistula repair, cervix flushed with vagina, invasive cancer of the cervix. ${ }^{1,14,15}$ In the present study, a uterine size consistent with or less than 12 weeks' gestation size was found in $49 \%$ of patients who had hysterectomy and of these only $26 \%$ had some form of pelvic adhesions. Those aged 45 years and above constituted $64 \%$ of the study population and $48 \%$ of the study population had parities of greater than four and hence were more likely to have had mobile uteri. Despite these findings, vaginal hysterectomy was done in only $10 \%$ of patients who all had uterovaginal prolapse. Previous studies in Nigeria had indicated that vaginal hysterectomy is apt to be technically more difficult for indications other than uterovaginal prolapse because severe pelvic adhesions are frequently seen in Nigerian women requiring hysterectomy hence the low incidence of vaginal hysterectomies 10,12 but the present study showed that $37 \%$ of the patients studied had some form of pelvic adhesions which is not in accord with this previous assumption. Uterine fibroids and cervical intraepithelial neoplasia accounted for $94 \%$ of indications for abdominal hysterectomies and vaginal hysterectomy is a treatment option for these conditions for patients who do not have any contraindications to the procedure. . $^{6,10,15}$ This further buttresses the point that more vaginal hysterectomies could have been done.

Postoperative complications were found in $29 \%$ of the patients that had abdominal hysterectomy while there were no complications among those who had vaginal hysterectomy, thereby giving further credence to previous reports that vaginal hysterectomy is associated with fewer complications than abdominal hysterectomy ${ }^{1-5}$ though the small number of those who had vaginal hysterectomy in our study may not be enough to confirm this assertion.

Consultants performed $53 \%$ of abdominal hysterectomies and all the vaginal hysterectomies while Senior Residents performed $47 \%$ of abdominal hysterectomies. This means that during the four years of the study, residents in training did not acquire much skill and certainly no proficiency in performing vaginal hysterectomies. A study in Japan had shown that a resident performing 25 vaginal hysterectomies or less over a three-year period is insufficient for acquisition of proficiency ${ }^{18}$ and hence residents in JUTH would need not only to perform vaginal hysterectomies but to do so in sufficient number to acquire proficiency in a procedure that has many advantages for patients. It has also been reported that application of practice guidelines would increase the number of and indications for vaginal hysterectomy in residency training programmes so that residents would have more opportunities to learn to perform the procedure. ${ }^{15}$

Our study showed the vaginal hysterectomy was underutilized in our institution and this may have deleterious effect on residents acquiring the skills to perform the procedure thereby limiting the treatment options these residents would be able to offer patients when they become specialists.

The limitation of the study was the inability to access some of the patients' records for analysis. The review of existing practice guidelines for hysterectomy, its adaptation to suit our local practice and its implementation is recommended as a means to increase the use of the vaginal route for hysterectomy and improve the training of residents in the art of this procedure.

\section{Acknowledgement}

The authors wish to thank Prof. R.H. Glew, Dr D. J. VanderJagt for their editorial advice on the initial drafts of this manuscript.

\section{REFERENCES}

1. Sheth SS. Vaginal hysterectomy. In: Studd J. (Ed) Progress in Obstetrics and Gynaecology. Volume Ten. Churchill Livingstone, Edinburgh.1993: 317-340.

2. Kovac SR. Clinical opinion: guidelines for hysterectomy. Am J Obstet Gynecol. 2004; 191: 635-40.

3. Brill AI. Hysterectomy in the $21^{\text {st }}$ Century: Different Approaches, 
Different Challenges. Clin Obstet Gynecol. 2006; 49: 722-35.

4. David-Montefiore E, Rouzier R, Chapron C, Darai E. Surgical routes and complications of hysterectomy for benign disorders: a prospective observational study in French University Hospitals. Hum Reprod. 2007; 22: 260-5.

5. Edozien LC. Hysterectomy for benign conditions. BMJ 2005; 330: 1457-1458.

6. Farquhar CM, Steiner CA Hysterectomy rates in the United States 19001997. Obstet Gynecol. 2002; 99: 229_ 234.

7. Chapron C, Laforest L, Ansquer Y, Fauconnier A, Fernandez B, Breart G, Dubuisson JB. Hysterectomy techniques used for benign pathologies: Results of a multicenter study. Hum Reprod 1999; 14: 2464-70.

8. Yusuf F, Siedlecky S. Hysterectomy and endometrial ablation in New South Wales, 1981 to 1994-1995. Aust N Z J
Obstet Gynaecol 1997; 37: 212-6.

9. Sobande AA, Eskander M, Archibong EI. Elective hysterectomy: A clinicopathological review from Abha catchment area of Saudi Arabia. WAJM 2005; 24: 31-35.

10. Onah HE, Ugona MC. An audit of hysterectomies in Enugu, Nigeria. Trop J Obstet Gynaecol 2004; 21: 58-60.

11. Onwuhafua PI, Oguntayo A, Adesiyun G, Obineche I, Akuse JT. Audit of hysterectomies in a group of private hospitals in Kaduna City, Northern Nigeria. Trop J Obstet Gynaecol 2005; 22: 16-20.

12. Onah HE,Ezegwui HU. Increasing the use of the vaginal route for hysterectomy in Nigerians: a critical appraisal. J Coll Med 2002; 7: 13-15.

13. Roberts OA, Okunlola MA. Abdominal hysterectomy for benign gynaecological conditions at Ibadan, Nigeria. Trop $J$ Obstet Gynaecol. 2001; 18: 19-23.
14. Kovac SR. Transvaginal hysterectomy: rational and surgical approach. Eur $J$ Obstet Gynecol Reprod Biol 2005; 120 : 232-3.

15. Kovac SR, Barhan S, Lister M, Tucker L, Bishop M, Das A. Guidelines for selection of the route of hysterectomy: application in a resident clinic population. Am J Obstet Gynecol 2002; 187: 1521-7.

16. Johnson N, Barlow D, Lethaby A, Tavender E, Curr E, Garry R. Methods of hysterectomy: systematic review and meta-analysis of randomized controlled trials. BMJ 2005; 330: 1478 81 .

17. Kovac SR. Guidelines to determine route of hysterectomy. Obstet Gynecol 1995; 85: 18-23.

18. Yaegashi N, Kuramoto M, Nakayama C, Nakano M, Yajima A. Resident gynecologists and total hysterectomy. Tohoku J Exp Med 1996; 178: 299-306. 